\title{
Treatment Outcome of Tuberculosis Patients in Selected Health Centres in Addis Ababa: a Five Year Retrospective Study
}

\author{
Yonas Alem', Solomon Gebre-Selassie ${ }^{2 *}$ \\ 'College of Health Sciences, Ambo University, Ambo, Ethiopia
}

${ }^{2}$ Department of Microbiology, Immunology and Parasitology, School of Medicine, College of Health Sciences, Addis Ababa University, Ethiopia

Article Info

\section{Article Notes}

Received: October 28, 2017

Accepted: December 18, 2017

\section{${ }^{*}$ Correspondence:}

Dr. Solomon Gebre-Selassie, Department of Microbiology, Immunology and Parasitology, School of Medicine, College of Health Sciences, Addis Ababa University, Ethiopia;

P. O. Box 21656/1000,

Tel. +251911199637;

Email: solomongst@yahoo.com

(C) 2017 Gebre-Selassie S. This article is distributed under the terms of the Creative Commons Attribution 4.0 International License.

\section{Keywords}

Tuberculosis

Treatment outcome

Trend analysis

Addis Ababa

\section{ABSTRACT}

Background: Tuberculosis is the leading cause of morbidity and mortality killing about 1.8 million people each year. Ethiopia is seventh on the list of high burden countries for tuberculosis. Monitoring outcome of tuberculosis treatment and identifying the specific reasons for unsuccessful treatment outcome are important in evaluating the effectiveness of tuberculosis control program.

Objective: This retrospective study was conducted to analyze the trend of tuberculosis and treatment outcomes at three health centers in Addis Ababa.

Methods: A total of 6178 tuberculosis patients visiting three health centers during 2012 were included in the study. Data of patients on demographic characteristics, year of treatment, disease category, and treatment outcomes were recorded. Data on treatment outcome as cured, treatment completed, failed, died, defaulted, or transferred were collected according to WHO recommendations.

Results: Of the 6178 patients, 3151(51\%) were males and 3027(49.0\%) were females. The mean age of the study subject was $32.07 \pm 14.0$. Smear positive pulmonary tuberculosis was $1670(27 \%)$, smear negative pulmonary tuberculosis in 2242(36.3\%) and extrapulmonary tuberculosis in 2262(36.6\%). Treatment outcome was successfully in $4919(79.6 \%)$, treatment failure in $42(0.7 \%)$, defaulters in 533(8.6\%), died in 396(6.4\%) and transferred out in $288(4.7 \%)$. Treatment success rate was steadily increased across the years from $76.2 \%$ in 2006 to $83.6 \%$ in 2010 ( $p<0.001$ ). Female tuberculosis patients had higher treatment success rate of $81.3 \%$ while males had $78 \%$ success $(p=0.001)$. Patients in the age group of $25-35$ years had a significantly low treatment success rate compared to the other age group $(p<0.001)$.

Conclusion: The treatment success rate of pulmonary and extrapulmonary tuberculosis patients treated at the 3 health centers was $79.6 \%$ which was lower than the WHO target of $85 \%$. The higher default and death rate in the study area is a serious public health concern. So community mobilization, defaulter tracing, improved supervision, health education and enhanced case detection rate should be implemented in order to increase the treatment success rate in the study area.

\section{Introduction}

Tuberculosis (TB) is an infectious disease caused by Mycobacterium tuberculosis. The most frequently involved organs are the lungs although other organs can be affected by the bacilli ${ }^{1}$. TB affects mostly adults in the economically productive age groups. Around two-thirds of cases are estimated to occur among people aged 15-59 years ${ }^{2}$. Tuberculosis is a major worldwide public health 
threat that kills approximately 1.8 million people each year ${ }^{3}$. One third of the global population is believed to be infected with M. tuberculosis bacilli complex, the causative agent of TB (4). In 2010, there were an estimated 8.8 million incident cases of TB (range, 8.5 million-9.2 million) globally, equivalent to 128 cases per 100,000 population ${ }^{2}$.

Ethiopia is $7^{\text {th }}$ on the list of 22 high burden countries for TB according to the latest World Health Organization (WHO) estimations. Tuberculosis is the leading cause of morbidity and the $2^{\text {nd }}$ cause of mortality after malaria ${ }^{5}$. Tuberculosis remains one of the major causes of morbidity and mortality in Ethiopia. According to hospital statistics data, tuberculosis is the leading cause of morbidity, the third cause of hospital admission, and the first cause of hospital death in Ethiopia 6 .

The WHO target for treatment success is $85 \%$ of all detected smear-positive cases $^{7}$. The main objectives of tuberculosis treatment are to cure the patient of tuberculosis, to prevent death from active tuberculosis or its late effects, to prevent relapse of tuberculosis, to prevent the development of drug resistance and to reduce transmission of the disease to others ${ }^{8}$. In the early 1990s, the WHO introduced the directly observed treatment, short course (DOTs) strategy as a cost-effective way to control TB and improve health ${ }^{9}$. A key component of DOTs strategy is to improve patient adherence to treatment and thus prevents the development of drug resistance ${ }^{10}$. The DOTs strategy was adopted in the first half of the 1990's in a few pilot sites, and eventually scaled up. In 2003, 95\% of the health facilities in the country worked under the DOTs ${ }^{6,11}$.

Monitoring outcome of tuberculosis treatment and identifying the specific reasons for unsuccessful treatment outcome are important in evaluating the effectiveness of tuberculosis control program ${ }^{12}$. The aim of the study was to analyze the trend of all types of TB and the treatment outcomes among TB patients in three health centres in Addis Ababa.

\section{Materials and Methods}

\section{Study design, place and period}

The study was conducted in Addis Ababa which consists of ten sub-cities with total population of 2.7 million people ${ }^{13}$. The study was conducted in Kirkos sub-city. The sub-city is one of the densely populated in Addis Ababa with a population density of 150 persons per hectare. A five year (January 2007 to December 2011) retrospective analysis of all types of tuberculosis and treatment outcomes was conducted based on the register of TB patients attending and in follow up in TB clinic at Kasanchis, Kirkos and Meshualekia Health Centres located Addis Ababa City.

\section{Study population and Data collection and Processing}

In the study period, a total of 6178 data of TB patients of all ages were retrieved from the data registry. Data variables collected included TB registration number, age, sex, type of TB disease and sputum smear results. Patients with incomplete data were excluded from the study. Treatment outcomes were recorded according to standardized National TB and Leprosy Control Program (NTLCP) classifications, based on WHO definitions ${ }^{6}$.

\section{Definitions of terms}

The following standard clinical case definitions of the NTLCP guideline adopted from WHO were used ${ }^{6,14}$ :

1. Smear-positive pulmonary tuberculosis (PTB+): A patient with at least two initial sputum smear examinations positive for acid fast bacilli (AFB) by direct microscopy, or A patient with one initial smear examination positive for AFB by direct microscopy and culture positive, or A patient with one initial smear examination positive for AFB by direct microscope and radiographic abnormalities consistent with active $\mathrm{TB}$ as determined by a clinician.

2. Smear-negative pulmonary tuberculosis (PTB-): A patient having symptoms suggestive of TB with at least 3 initial smear examinations negative for AFB by direct microscopy, and

a. No response to a course of broad-spectrum antibiotics, and

b. Again three negative smear examinations by direct microscopy, and

c. Radiological abnormalities consistent with pulmonary tuberculosis, and

d. Decision by a clinician to treat with a full course of antituberculosis or a patient whose diagnosis is based on culture positive for $\mathrm{M}$. tuberculosis but three initial smear examinations negative by direct microscopy.

3. Extra-pulmonary tuberculosis (EPTB): TB in organs other than the lungs, proven by one culturepositive specimen from an extra-pulmonary site or histopathological evidence from a biopsy, or TB based on strong clinical evidence consistent with active EPTB and the decision by a physician to treat with a full course of anti-TB therapy.

\section{According to NTLCP guidelines Treatment outcomes are divided into seven categories.}

1. Cured: A initially smear-positive patient who is sputum smear-negative at, or one 'month' prior to, the completion of treatment and on at least one previous occasion (usually at the end of the $2^{\text {nd }}$ or $5^{\text {th }}$ month of treatment). 
2.Treatment completed: A patient who completed treatment but for whom smear results are not available at $5^{\text {th }}$ month or one month prior to the completion of treatment.

3. Treatment failure: A patient who remains or becomes again smear-positive at the end of 5 "month" or later during treatment. Or a patient who was PTB-negative at the beginning and turned out smear-positive at the end of the intensive phase.

4. Died: a patient who dies for any reason during the course of treatment.

5. Defaulter: A patient who has been on treatment for at least 4 weeks and whose treatment was interrupted for 8 or more consecutive weeks.

6. Transfer out: A patient who started treatment and has been transferred to another reporting unit and for whom the treatment outcome is not known at the time of evaluation of treatment results.

7. Treatment success: The sum of patients who are declared "cured" and those who have "completed" treatment.

\section{Data entry and analysis}

Data was entered by Epi InfoVersion 3.5 and then exported to SPSS for window version 16 and analyzed. For categorical data, comparisons were made using 95\% confidence interval, Chi-square and odds ratio. Bivariate analysis using logistic regression model was used to analyse the association between treatment outcome and potential predictor variables. P-value of $<0.05$ consider indicative of a statistically significant difference.

\section{Ethical Considerations}

This project was ethically cleared and approved and by the Ethical committee of the Department of Microbiology, Immunology and Parasitology of the School of Medicine of Addis Ababa University. Patients' identifications were kept confidential and data were analyzed anonymously.

\section{Results}

\section{Sociodemographic characteristics of tuberculosis patients}

Of the 6178 TB patient registered at Kasanchis, Meshalokia and Kirkos health centres, 3151(51.0\%) were males and 3027(49.0\%) were females with male to female ratio of $1: 0.9$. The mean age of the study population was $32.073 \pm 14.004$ years (range: 4 month-88 years). Of these, $318(5.1 \%)$ were children under 15 years of age. Majority of the patients $(>75 \%)$ were in the younger age category between 15 and 44. Of these, 1989(32.2\%) were in the age group 25-34 years. PTB comprised of 3912(63.3\%) while
2266(36.7\%) had EPTB. The five year trend showed that of smear-negative PTB cases were higher, 2242(36.3\%) compared to smear-positive PTB 1670(27\%) (Table 1).

\section{Trends of Tuberculosis}

The trend of all types of tuberculosis in the study area steadily decreases over the study period from $21.6 \%$ in 2007 to $19.5 \%$ in 2011 . The number of smear-negative PTB cases increased over the study period compared to the other types. But the rate of EPTB cases decreased significantly from $22.6 \%$ in 2007 to $15.8 \%$ in 2011 . Both EPTB 2266(36.7\%) and smear-negative PTB 2242(36.3\%) remained high compared to smear-positive PTB 1670(27\%) cases across the health centers. Kirkos health centre had the highest cases comprising of 2369(38.3\%) followed by Kasanchis, 1960(31.7\%) and Meshalokia, 1849(29.9\%). The highest smear-positive PTB 669(40.1\%) and smearnegative PTB 942(42\%) patients were from Kirkos health centre. On the other hand, the highest EPTB patients $848(37.4 \%)$ were from Kasanchis health center (Table 2).

\section{Disease Category}

Most of the tuberculosis cases, 5026(81.4\%) were new, while $287(4.6 \%)$ were relapse, $17(0.3 \%)$ failure, $15(0.2 \%)$ defaulter, $169(2.7 \%)$ transfer, and $664(10.7 \%)$ others. There was a significantly higher proportion of relapse $(\mathrm{OR}=1.582, \mathrm{CI}=1.54-1.626)$ and defaulters (OR=1.37, 95\%CI $=1.122-1.672)$ in PTB than EPTB (97.6\% vs $2.4 \%$ and $86.7 \%$ vs $13.3 \%$ ), respectively (Fig 1).

\section{Organ involvement of extrapulmonary tuberculosis}

Of the EPTB, $630(27.8 \%)$ were confirmed by different

Table 1: General Characteristics of Study Population $(N=6178)$ in three Health Centers.

\begin{tabular}{|l|c|c|}
\hline Characteristics & Frequency & Percent \\
\hline Sex & & 51.0 \\
\hline Male & 3151 & 49.0 \\
\hline Female & 3027 & \\
\hline Age Group (years) & & 5.1 \\
\hline $0-14$ & 318 & 26.1 \\
\hline $15-24$ & 1614 & 32.2 \\
\hline $25-34$ & 1989 & 18.5 \\
\hline $35-44$ & 1140 & 9.5 \\
\hline $45-54$ & 586 & 5.1 \\
\hline $55-64$ & 314 & 3.5 \\
\hline$\geq 65$ & 217 & \\
\hline Type of TB & & 27.0 \\
\hline PTB+ & 1670 & 36.3 \\
\hline PTB- & 2242 & 36.7 \\
\hline EPTB & 2266 & 100 \\
\hline Total & 6178 & \\
\hline
\end{tabular}

PTB $+=$ Smear positive Pulmonary Tuberculosis; PTB- = Smear negative Pulmonary Tuberculosis; EPTB = Extrapulmonary Tuberculosis 
Table 2: Trends of tuberculosis of all cases $(\mathrm{N}=6178)$ in three Health Centers.

\begin{tabular}{|c|c|c|c|c|}
\hline \multirow{2}{*}{ Health Centre } & \multicolumn{3}{|c|}{ Type of TB, No (\%) } & \multirow{2}{*}{$\begin{array}{l}\text { Total } \\
\text { No (\%) }\end{array}$} \\
\hline & PTB+ & PTB- & EPTB & \\
\hline Kasanchis & $470(28.1)$ & $643(28.7)$ & $848(37.4)$ & 1960(31.7) \\
\hline Meshalokia & $531(31.8)$ & $657(29.3)$ & $661(29.2)$ & 1849(29.9) \\
\hline Kirkos & $669(40.1)$ & $942(42.0)$ & $757(33.4)$ & $2369(38.3)$ \\
\hline Total & $1670(27.0)$ & $2242(36.3)$ & $2266(36.7)$ & $6178(100)$ \\
\hline
\end{tabular}

methods. The most frequently involved organs were lymph nodes 291(46.2\%), pleura $164(26.1 \%)$ and miliary $70(11.1 \%)$. Of these, lymph node 93(32\%), miliary $23(32.9 \%)$, Peritonitis $18(31.6 \%)$ occurred at higher proportion with in age group 25-34. TB pleuritis $54(32.9 \%)$ remained highest in the age group 15-24. Of the 291 cases of TB lymphadenitis, females comprised of 167(57.4\%). On the other hand, TB pleuritis was slightly higher in males $92(56.1 \%)$ than in females (Table 3 ).

\section{Disease category}

Most of the TB cases were new 5026(81.4\%) and relapse $287(4.6 \%)$, Failure $17(0.3 \%)$, defaulters $15(0.2 \%)$, Transfer in 169(2.7\%), others, 664(10.7\%). There was a significantly higher proportion of relapse (OR=1.582, C.I. $=1.54-1.626)$ and defaulters (OR=1.37, $\mathrm{CI}=1.122-1.672$ ) in PTB than EPTB (97.6\% vs $2.4 \%, 86.7 \%$ vs $13.3 \%$ ) respectively (Figure 1 ).

\section{Treatment outcome of tuberculosis}

The treatment success proportion was increasing across the year $76.2 \%$ (2007), 81.9\% (2008), 78.5\% (2009), $78.2 \%$ (2010) then $83.6 \%$ (2011). The highest treatment success rate (83.6\%; $\mathrm{p}<0.001,95 \% \mathrm{CI}=0.506-0.754$ ) was observed in 2011 as compared to across the years in the study period. The default and death rate decrease steadily across the years. The highest default and death rate was $10.7 \%$ and $8 \%(\mathrm{p}<0.001,95 \% \mathrm{CI}=1.595-3.006)$ in 2009 and 2007, respectively (Table 4).

Male patients had higher default rate of $10 \%(\mathrm{p}<0.001$; $\mathrm{OR}=1.472$, 95\%C.I. 1.222-1.772) than females. The death rate increased as age increased, from $13(4.1 \%)$ in under 15 children to $23(10.6 \%)$ in the age groups $\geq 65$ years $(\mathrm{P}=00.7)$. Smear-negative PTB patients had higher death rate of $8.1 \%$ than smear-positive PTB $(\mathrm{p}=0.002$, OR=1.498, 95\%CI, 1.157-1.94) (Table 5).

Table 3: Frequency of organ involvement $(n=630)$ among extrapulmonary tuberculosis cases in three Health Centers.

\begin{tabular}{|c|c|c|c|c|c|c|}
\hline \multirow[b]{2}{*}{ Characteristics } & \multicolumn{5}{|c|}{ Site of EPTB involved, No (\%) } & \multirow[b]{2}{*}{$\begin{array}{l}\text { Total } \\
\text { No (\%) }\end{array}$} \\
\hline & $\begin{array}{c}\text { Lymph node TB } \\
\text { No (\%) }\end{array}$ & $\begin{array}{c}\text { Pleural TB } \\
\text { No (\%) }\end{array}$ & $\begin{array}{c}\text { Miliary TB } \\
\text { No (\%) }\end{array}$ & $\begin{array}{c}\text { Peritoneal TB } \\
\text { No (\%) }\end{array}$ & $\begin{array}{l}\text { Others } \\
\text { No (\%) }\end{array}$ & \\
\hline \multicolumn{7}{|l|}{ Sex } \\
\hline Male & $124(42.6)$ & $92(56.1)$ & $36(51.4)$ & $31(54.4)$ & 19(39.6) & $302(47.9)$ \\
\hline Female & $167(57.4)$ & $72(43.9)$ & $34(48.6)$ & $26(45.6)$ & $29(60.4)$ & $328(52.1)$ \\
\hline \multicolumn{7}{|l|}{ Age Group } \\
\hline $0-14$ & $26(8.9)$ & $8(4.9)$ & $5(7.1)$ & $2(3.5)$ & $5(10.4)$ & $46(7.3)$ \\
\hline $15-24$ & $82(28.2)$ & $54(32.9)$ & $13(18.6)$ & $15(26.3)$ & $9(18.8)$ & $173(27.5)$ \\
\hline $25-34$ & $93(32.0)$ & $44(26.8)$ & $23(32.9)$ & $18(31.6)$ & $18(37.5)$ & 196(31.1) \\
\hline $35-44$ & $53(18.2)$ & $26(15.9)$ & $13(18.6)$ & $14(24.6)$ & $8(16.7)$ & $114(18.1)$ \\
\hline $45-54$ & $23(7.9)$ & $16(9.8)$ & $12(17.1)$ & $3(5.3)$ & $7(14.6)$ & $61(9.7)$ \\
\hline $55-64$ & 10(3.4) & $7(4.3)$ & $4(5.7)$ & $3(5.3)$ & $0(0)$ & $24(3.8)$ \\
\hline$\geq 65$ & $4(1.4)$ & $9(5.5)$ & $0(0)$ & $2(3.5)$ & $1(2.1)$ & $16(25.0)$ \\
\hline Total & $291(46.2)$ & $164(26.1)$ & $70(11.1)$ & $57(9.0)$ & $48(7.6)$ & $630(100)$ \\
\hline
\end{tabular}

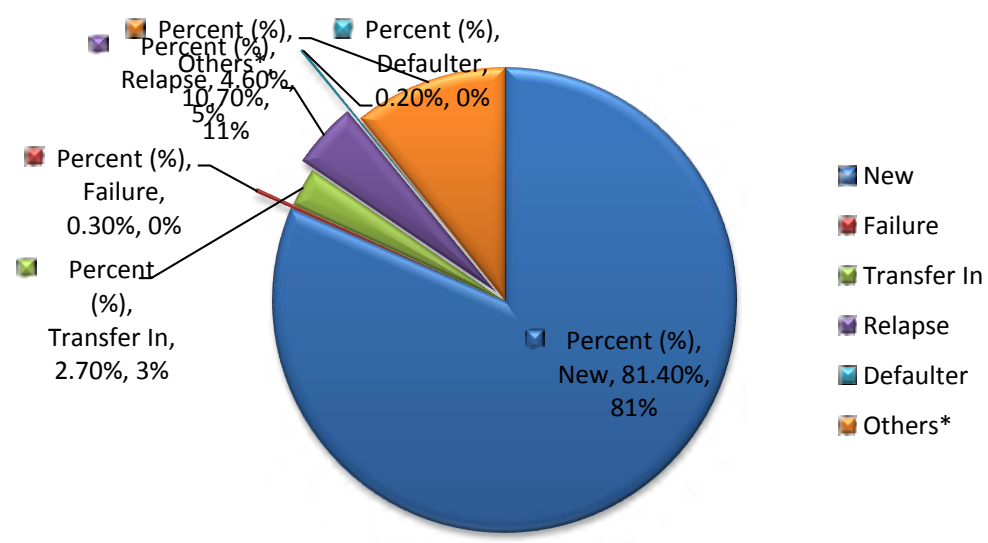

Figure 1: Disease category of all cases of tuberculosis ( $N=6178)$, Kirkos sub-city health centers 
Table 4: Treatment outcome of all TB cases across the year in three Health Centres

\begin{tabular}{|c|c|c|c|c|c|c|}
\hline \multirow[b]{2}{*}{$\begin{array}{l}\text { Year Treatment } \\
\text { Started }\end{array}$} & \multicolumn{5}{|c|}{ Treatment Outcomes } & \multirow{2}{*}{$\begin{array}{l}\text { Total } \\
\text { No (\%) }\end{array}$} \\
\hline & $\begin{array}{c}\text { Treatment success } \\
\text { No (\%) }\end{array}$ & $\begin{array}{c}\text { Treatment failure } \\
\text { No }(\%)\end{array}$ & $\begin{array}{l}\text { Default } \\
\text { No (\%) }\end{array}$ & $\begin{array}{c}\text { Died } \\
\text { No (\%) }\end{array}$ & $\begin{array}{c}\text { Transfer out } \\
\text { No (\%) }\end{array}$ & \\
\hline 2007 & $1017(76.2)$ & $10(0.7)$ & 139(10.4) & $107(8.0)$ & $62(4.6)$ & $1335(21.6)$ \\
\hline 2008 & 1025(81.9) & $3(0.2)$ & $107(8.6)$ & $63(5.0)$ & $53(4.2)$ & $1251(20.2)$ \\
\hline 2009 & $946(78.5)$ & $12(1.0)$ & $129(10.7)$ & $72(5.0)$ & $46(3.8)$ & $1205(19.5)$ \\
\hline 2010 & $924(78.2)$ & $9(0.8)$ & $88(7.4)$ & $86(7.3)$ & $75(6.3)$ & $1182(19.1)$ \\
\hline 2011 & $1007(83.6)$ & $8(0.7)$ & $70(5.8)$ & $68(5.6)$ & $52(4.3)$ & $1205(19.5)$ \\
\hline Total & 4919(79.6) & $42(0.7)$ & $533(8.6)$ & $396(6.4)$ & $288(4.6)$ & $6178(100)$ \\
\hline
\end{tabular}

Table 5: Treatment outcome of tuberculosis by sex, age group and tuberculosis type in three Health Centres.

\begin{tabular}{|c|c|c|c|c|c|c|}
\hline \multirow[b]{2}{*}{ Characteristics } & \multicolumn{5}{|c|}{ Treatment Outcome, No (\%) } & \multirow[b]{2}{*}{$\begin{array}{l}\text { Total } \\
\text { No (\%) }\end{array}$} \\
\hline & $\begin{array}{c}\text { Treatment success } \\
\text { No (\%) }\end{array}$ & $\begin{array}{l}\text { Treatment failure } \\
\text { No (\%) }\end{array}$ & $\begin{array}{l}\text { Default } \\
\text { No (\%) }\end{array}$ & $\begin{array}{c}\text { Died } \\
\text { No (\%) }\end{array}$ & $\begin{array}{c}\text { Transfer out } \\
\text { No (\%) }\end{array}$ & \\
\hline \multicolumn{7}{|l|}{ Sex } \\
\hline Male & $2459(78.0)$ & $21(0.7)$ & $315(10.0)$ & $194(6.2)$ & $162(5.1)$ & $3151(51.0)$ \\
\hline Female & $2460(81.7)$ & $21(0.7)$ & $218(7.2)$ & $202(6.7)$ & $126(4.2)$ & $3027(49.0)$ \\
\hline \multicolumn{7}{|c|}{ Age group (years) } \\
\hline $0-14$ & $276(86.8)$ & $1(0.3)$ & $19(6.0)$ & $13(4.1)$ & $9(2.8)$ & $318(5.1)$ \\
\hline $15-24$ & $1279(79.2)$ & $12(0.7)$ & $143(8.9)$ & $71(4.4)$ & $109(6.8)$ & $1615(26.1)$ \\
\hline $25-34$ & $1551(78.0)$ & 19(1.0) & $187(9.4)$ & 133(6.7) & $101(5.1)$ & $1991(32.2)$ \\
\hline $35-44$ & $920(80.7)$ & $5(0.4)$ & $93(8.2)$ & $83(7.3)$ & $38(3.3)$ & $1139(18.4)$ \\
\hline $45-54$ & $470(80.2)$ & $5(0.9)$ & $46(7.8)$ & $46(7.8)$ & $18(3.1)$ & $585(9.5)$ \\
\hline $55-64$ & $253(80.6)$ & $0(0)$ & $26(8.3)$ & $27(8.6)$ & $7(2.2)$ & $313(5.1)$ \\
\hline$\geq 65$ & 169(77.9) & $0(0)$ & $19(8.8)$ & $23(10.6)$ & $6(2.8)$ & $217(3.5)$ \\
\hline \multicolumn{7}{|l|}{ Type of TB } \\
\hline PTB+ & $1297(77.6)$ & $42(2.6)$ & $144(8.6)$ & $93(5.6)$ & $94(5.6)$ & $1670(27.0)$ \\
\hline PTB- & $1772(79.0)$ & $0(0)$ & $191(8.5)$ & $182(8.1)$ & $97(4.3)$ & $2242(36.3)$ \\
\hline EPTB & $1851(81.7)$ & $0(0)$ & $198(8.7)$ & $121(5.3)$ & $97(4.3)$ & $2266(36.7)$ \\
\hline
\end{tabular}

Table 6: Odds ratio, $95 \% \mathrm{Cl}$, and P-value of treatment outcome by sex, age group and type of tuberculosis in three Health Centres

\begin{tabular}{|c|c|c|c|c|c|}
\hline \multirow{2}{*}{ Characteristics } & \multicolumn{2}{|c|}{ Treatment Outcome } & \multirow{2}{*}{ Odds ratio } & \multirow{2}{*}{$95 \% \mathrm{Cl}$} & \multirow{2}{*}{ P-value } \\
\hline & Yes (\%) & No (\%) & & & \\
\hline \multicolumn{6}{|l|}{ Sex } \\
\hline Male & $2459(78)$ & $692(22)$ & 0.952 & - & - \\
\hline Female & $2462(81.3)$ & $565(18.7)$ & 1.226 & $1.083-1.388$ & 0.001 \\
\hline \multicolumn{6}{|l|}{ Age Group } \\
\hline $0-14$ & $276(86.8)$ & $42(13.2)$ & 0.152 & - & - \\
\hline $15-24$ & $1279(79.2)$ & $335(20.8)$ & 1.702 & $1.204-2.406$ & 0.003 \\
\hline $25-34$ & $1551(78)$ & $438(22.0)$ & 1.856 & $1.319-2.611$ & 0.001 \\
\hline $35-44$ & $920(80.7)$ & $220(19.3)$ & 1.571 & $1.100-2.244$ & 0.013 \\
\hline $45-54$ & $470(80.2)$ & $116(19.8)$ & 1.622 & $1.106-2.379$ & 0.013 \\
\hline $55-64$ & $253(80.6)$ & 61(19.4) & 1.584 & $1.032-2.432$ & 0.35 \\
\hline$>=65$ & $169(77.9)$ & $48(22.1)$ & 1.86 & $1.183-2.945$ & 0.007 \\
\hline \multicolumn{6}{|l|}{ Type of TB } \\
\hline PTB & $3068(78.4)$ & $844(21.6)$ & 0.852 & $\ldots$ & - \\
\hline EPTB & $1851(81.7)$ & $415(18.3)$ & 1.174 & $1.029-1.34$ & 0.01 \\
\hline
\end{tabular}

Female TB patients had higher treatment success rate $(81.3 \%$ Vs $78 \% ; \mathrm{p}=0.001, \mathrm{OR}=1.226$, C.I. $=1.083-1.388)$ than males. Patients with EPTB had higher treatment success rate $(81.7 \%)(\mathrm{p}<0.001, \mathrm{OR}=1.174 ; 95 \%$ CI 1.029 -
1.34) than PTB patients. In addition, patients in the age group of 25-34 years had a significantly low treatment success rate compared to the other age group (78\%; $\mathrm{p}<0.001, \mathrm{OR}=1.571,95 \% \mathrm{CI}=1.10-2.24$ ) (Table 6). 


\section{Discussion}

In the present study, of the study subjects ( $\mathrm{n}=6178), 51 \%$ were males and $49 \%$ were females. This is in agreement with the difference is partly due to the fact that women have less access to diagnostic facilities in some settings, but the broader pattern also reflects real epidemiological differences between men and women, both in exposure to infection and in susceptibility to disease elsewhere in the world. From the study subjects, $63.3 \%$ had pulmonary tuberculosis and $36.7 \%$ had EPTB disease. This result is similar to the previous reports in Ethiopia (67.4\% vs $32.3 \%$ [15]; $71.7 \%$ vs $28.3 \%{ }^{16}$ and Hong Kong $(77.8 \%)^{17}$. In the present study, most of the patients, (81.4\%) were new cases. This is lower compared to a previous report from Ethiopia ${ }^{11}$ which was $93.6 \%$, and another study from Hong Kong by Noertjojo et al, $2002^{17}$ which was $90.1 \%$. This shows that the detection and treatment of new cases is consistently increasing.

The organ involvement in EPTB identified based on clinical indicators were lymph nodes $(46.2 \%)$, pleura (26.1\%) and miliary (11.1\%). This is similar with a study done in Turkey, which showed that TB lymphadenitis was the commonest EPTB ${ }^{18}$. However, a study done in Hong also showed that common organ was pleura $(41.2 \%)$, followed by lymph node $(36.5 \%)^{17}$. Regarding to site of extrapulmonary involvement lacks consistency in identification this might be due to unavailability of skilled man power and diagnostic materials for other alternative type of diagnosis. In this study, tuberculous pleural effusion was found in 164(26.1\%). Previous studies indicate that TB pleural effusion accounted for approximately $5 \%$ of disease due to $M$. tuberculosis, the second most common form of EPTB after lymphatic involvement ${ }^{19}$.

Of the 22 HBCs, 15 reached the $85 \%$ target. The treatment success for Ethiopia was $84 \%{ }^{2}$. The present study found that treatment outcome of all tuberculosis patients under DOTs programme at the health centres was $79.6 \%$ which is less than the target of WHO. Similarly, previous studies done in Ethiopia by Shargie et $\mathrm{al}^{11}$ and Tessema et $\mathrm{al}^{16}$ showed even lower treatment success rates of $49 \%$ and $29.5 \%$, respectively. On the other hand, the present study showed lower than a recent study by Endris et al (2014) who reported $94.8 \%$ successful treatment outcome in a health centre in northern Ethiopia ${ }^{20}$. Treatment failure, default and death rate of the study subjects need attention in order to attain the target treatment success rate.

The present study revealed that female patients had higher treatment success rate than males $(p<0.001)$. Furthermore, patients in the productive age group of 25-34 had low treatment success compared to other age group $(78 \%, \mathrm{p}<0.001)$. This is in line with the previous studies by Shargie and Lindtjørn ${ }^{15}$ and Tessema et $\mathrm{al}^{16}$. Patients with EPTB had higher treatment success rate than PTB patients $(\mathrm{p}<0.001)$. Of the PTB patients, smear-negative PTB patients $79 \%$ had higher treatment success rate than smear-positive PTB patients (77.6\%). The treatment success rate progressively increased across the study period. A higher treatment success rate of $83.6 \%$ was obtained during 2011 ( $\mathrm{p}<0.001)$. This is similar to the ten years DOTs experience study conducted in Addis Ababa by Woldeyohannes et $\mathrm{al}^{21}$.

This study demonstrates that the default rate of tuberculosis patients $(8.6 \%)$ was higher than the average $6.2 \%$ among the $22 \mathrm{HBCs}^{22}$. On the other hand, the default rate of the present study is lower than the study at Gondar University teaching hospital and northwest Ethiopia and also the study done in Taiwan. There is a significantly decrease of default rate across the years from $10.4 \%$ in 2006 to $5.8 \%$ in 2010. According to the study done by Farah et $\mathrm{al}^{23}$ from Norway, the reason for higher default rate might be patients frequently change their address and stigma related to TB. So proper implementation of DOTs strategy ${ }^{24}$ and conventional approach of treatment supervision; social and cultural factors that might play role need to be explored by Shargie and Lindtjørn ${ }^{15}$. The higher default rate in the study area might be due to weak patient tracing strategy, patients frequently changing their address and lack of knowledge about the patients' socio-cultural background by the health professionals.

The death rate of tuberculosis patients in the study was $6.4 \%$ and the trend across the years had shown a decrease from $8 \%$ in 2007 to $5.6 \%$ in 2011. This is in agreement with the study done at Gondar University teaching hospital by Tessema et $\mathrm{al}^{16}$. As presented, the death rate of tuberculosis patients increase as the age group increases from $4.1 \%$ in $0-14$ years to $18.6 \%$ in greater than 55 years of age. The study finding is similar to the previous study done in Ethiopia (Tessema et $\mathrm{al}^{16}$, and elsewhere ${ }^{24,25}$. Older patients had high risk of death; this is due to high age and concomitant diseases in which they developed. The treatment failure rate of HBCs varied from $0.1 \%$ to $9.1 \%$ with the average treatment failure of $1.5 \%$ in the area. This is linked to high rates of HIV infection, drug resistance and weak health services ${ }^{25}$. The treatment failure of the current study area was $0.7 \%$, which is lower than the average treatment failure of the 22 HBCs. This might be low prevalence of multidrug resistant tuberculosis (MDR) and better health service provision in the study area.

In the present investigation the number of smearnegative TB cases increase from $19.9 \%$ to $23.6 \%$ throughout the study period. This finding is similar to the a ten and five year trend analysis done in Addis Ababa and Gondar University Teaching Hospital by Woldeyohannes et $\mathrm{a}^{21}$ and Tessema et $\mathrm{al}^{16}$, respectively. The EPTB cases $(36.7 \%)$ were the highest cases in the study area as compared to smear- 
negative PTB and smear-positive PTB cases. The study area has high HIV prevalence and this might result in HIV-TB co infection. In addition HIV infected patients have less cavity formation due to their compromised immune response which gives sputum smear negative result ${ }^{26,27}$.

The limitation of the present study, some factors which affect the successful treatment outcome such as comorbidities like HIV infections and behavioral risk factors of the patient was not recorded. HIV serostatus of the study subjects lacks uniformity which was not included in the present study.

\section{Conclusion}

The treatment success rate of pulmonary and extrapulmonary tuberculosis patients treated at health centers found at Kirkos sub-city was lower $79.6 \%$ which falling towards the WHO target for treatment success $85 \%$. The higher treatment failure (default and death) rate in the study area is a serious public health concern that needs to be address urgently. Smear positive pulmonary tuberculosis cases were very low as compared to extrapulmonary and smear negative pulmonary tuberculosis cases. Lymph node and pleural tuberculosis were higher among the extrapulmonary tuberculosis patients. The highly affected groups were the younger age groups (25-34 years of age) which also had the lowest treatment success rate. The trend of tuberculosis successful treatment outcome increased throughout the study period. Smear negative pulmonary tuberculosis cases increased throughout the study period than extrapulmonary and smear positive pulmonary tuberculosis cases.

\section{Competing Interests}

The authors declare that they have no competing interests.

\section{Authors' Contribution}

YA conceived the study, designed, participated in data collection, conducted data analysis, entered data and interpreted the results. SG reviewed the initial and final drafts of the paper, and drafted the paper for publication. All authors read and approved the final paper.

\section{Acknowledgements}

We thank all the TB clinic staff of Kirkos, Kasanchis and Meshalokia health centres for their support in providing information for the study.

\section{References}

1. Gonzalez OY, Adams G, Teeter LD. Extra-pulmonary manifestations in a large metropolitan area with a low incidence of tuberculosis. Int J Tuberc Lung Dis. 2003; 7: 1178-1185.

2. WHO. World Health Organization Report: global tuberculosis control. Geneva, Switzerland. 2011.

3. Lantos-Hyde. United States Government Tuberculosis Strategy, USA, 2004.
4. Lauzardo M, Ashkin D. Pathophysiology at the dawn of the new century. Chest. 2000; 117: 1455-1473.

5. Meeussen A. A short term consultancy on tuberculosis prevention and control at community level in Ethiopia. 2010, Addis Ababa, FDRE, Ministry Of Health.

6. Ministry of Health of Ethiopia (MOH): Tuberculosis, Leprosy and TB/ HIV Prevention and Control Programme Manual, 2008.

7. World Health Organization (WHO): The world health report changing history. Geneva, Switzerland, 2004.

8. Maher D. Management of tuberculosis in children. Intern J Tuberc Lung Dis. 2006; 10: 1205-1211.

9. Keeler E, Perkins MD, Small P, et al. Reducing the global burden of tuberculosis: the contribution of improved diagnostics. Nature Review Microbiol. 2006; 49-57.

10. Chennaveerappa PK, Siddharam SM, Halesha BR, et al. Treatment outcome of tuberculosis patients registered at dots centre in a teaching hospital, South India. Intern J Biological Med Res. 2011; 2: 487-489.

11. Shargie EB. Trends, challenges and opportunities in tuberculosis control in rural Ethiopia: epidemiological and operational studies in a resource-constrained setting. 2006.

12. Sunday O, Oladimeji O, Ebenezer F, et al. Treatment Outcome of Tuberculosis Patients Registered at DOTS Centre in Ogbomoso, Southwestern Nigeria: A 4-Year Retrospective Study. Tuberc Res Treat. 2014, Article ID 201705, 5 pages.

13. Central Statistical Authority and ORC Marco, Demographic and Health Survey, 2005. Addis Ababa, Ethiopia and Calverton, Maryland, USA. 2006.

14. Ministry Of Health (MOH) of Ethiopia: Tuberculosis Prevention and Control. Annual Bulletin. Addis Ababa, Health Promotion and Disease Prevention, 2010.

15. Sharge, Lindtjorn. DOTs improves treatment outcomes and service coverage for tuberculosis in South Ethiopia: a retrospective trend analysis. BMC Public Health. 2005; 5: 62

16. Tessema B, Muche A, Bekele A, et al. Treatment outcome of tuberculosis patients at Gondar university teaching hospital, Northwest Ethiopia. A five - year retrospective study. BMC Public Health. 2009; 371.

17. Noertjojo K, Tam CM, Chan SL, et al. Extra-pulmonary and pulmonary tuberculosis in Hong Kong. Int J Tuberc Lung Dis. 2002; 6: 879-886.

18. Musellim B, Erturan S, Duman ES, et al. Comparison of extrapulmonary and pulmonary tuberculosis cases: factors influencing the site of reactivation. Int J Tuberc Lung Dis. 2005; 9: 1220-1223.

19. Baumann MH, Nolan R, Petrini $M$, et al. Pleural tuberculosis in the United States: incidence and drug resistance. Chest 2007; 131: 1125.

20. Endris M, Moges F, Belayhun Y, et al. Treatment outcome of tuberculosis patients at Enfraz Health Center, Northwest Ethiopia: A Five-Year Retrospective Study. Tuberculosis Research and Treatment. 2014 Article ID 726193, 7 pages

21. Woldeyohannes D, Kebede N, Erku W, et al. Ten year experience of directly observed treatment short-course (DOTs) therapy for tuberculosis in Addis Ababa, Ethiopia. Ethiop Med J. 2011; 49: 221-9.

22. World Health Organization Report: global tuberculosis control. Geneva, Switzerland, 2010.

23. Farah MG, Tverdal A, Steen TW, et al. Treatment outcome of new culture positive pulmonary tuberculosis in Norway. Bio Med Central. 2005; 5: 14.

24. Jen-Jyh L, Rong-Lun W, Yeong-Sheng L, et al. Treatment outcome of pulmonary tuberculosis in Eastern Taiwan- experience at a medical center. J Formos Med Assoc 2007; 106: 25-30. 
25. Riekstina V, Leimane V, Holtz TH, et al. Treatment outcome cohort analysis in an integrated DOTS and DOTS-plus TB program in Latvia. Int J Tuberc Lung Dis. 2007; 11: 585-587.

26. WHO. World Health Organization Report: global tuberculosis control. Geneva, Switzerland, 2009.
27. Siddiqi K, Lambert ML, Walley J. Clinical diagnosis of smear-negative pulmonary tuberculosis in low-income countries: the current evidence. Lancet Infect Dis. 2003; 3: 288-296. 